\title{
Carmen Miranda en Hollywood (1939-1945): en el centro de la pantalla, al borde de la historia
}

Paula Orozco-Espinel ${ }^{1}$

Recibido: 01/03/2019

Aprobado por pares: 25/06/2019
Enviado a pares: 20/03/2019

Aceptado: 26/06/2019

DOI: 10.5294/pacla.2019.22.4.8

Para citar este artículo / to reference this article / para citar este artigo Orozco-Espinel, P. (2019). Carmen Miranda en Hollywood (1939-1945): en el centro de la pantalla, al borde de la historia. Palabra Clave, 22(4), e2248. DOI: https://doi.org/10.5294/ pacla.2019.22.4.8

\section{Resumen}

En este artículo, hago un análisis del personaje que Carmen Miranda — famosa actriz y cantante aún hoy recordada como la bombshell brasileñainterpretó entre 1939 y 1945 . Me propongo explorar cómo su presencia en pantalla da cuenta de los deseos y miedos estadounidenses, asociados en parte a la Segunda Guerra Mundial, pero sobre todo en diálogo con imaginarios sobre raza y género. Para ello, hago un análisis de las comedias musicales en que apareció la actriz y me concentraré en su rol en las narrativas. Evidencio que, si bien los personajes representados por Miranda son centrales en los números musicales, aparecen poco en escena durante el resto de las películas y no llevan a cabo acciones que permitan el desarrollo de las historias. Asimismo, demuestro que Miranda no satisfizo los estándares de integración hemisférica propuestos por la Oficina de Asuntos Interamericanos —organismo gubernamental estadounidense creado para afianzar la cooperación interamericana durante la guerra - en tanto perpetuaba estereotipos negativos sobre América Latina. De lo anterior, sos-

1 https://orcid.org/0000-0003-2916-9603. Universidad Nacional de Colombia, Colombia. mporozcoe@unal.edu.co 
tengo que la función de la actriz estuvo relacionada con atraer y complacer al público estadounidense. Ella hizo uso de su capacidad para ser cómica y sexi al mismo tiempo, que, sostengo, se derivaba del lugar que ocupaba en la jerarquía racial de la época. Mi trabajo es novedoso en tanto da por sentado algunos aspectos sobre los que se ha llamado la atención, tales como el vestuario y el acento de Carmen Miranda, y se concentra en la narrativa de sus películas, punto hasta ahora inexplorado.

\section{Palabras clave (Fuente: tesauro de la Unesco)}

Carmen Miranda; representación; mujeres latinoamericanas; política de la buena vecindad; Hollywood; comedias musicales; historia norteamericana; historia del cine; cine; estereotipo. 


\section{Carmen Miranda in Hollywood (1939- 1945): In the Middle of the Screen, on the Edge of History}

\section{Abstract}

In this article, I analyze the character that Carmen Miranda - a famous actress and singer still remembered today as the Brazilian bombshell- performed between 1939 and 1945. I intend to explore how her presence on the screen accounts for American desires and fears, associated in part with World War II, but especially in relation to race and gender imaginaries. For this, I examine the musical comedies in which the actress appeared and focus on her role in narratives. I note that, while the characters performed by Miranda are central in musicals acts, they appear little on the scene for the rest of the films and do not carry out actions that contribute to the plot. I also show that Miranda did not meet the hemispheric integration standards proposed by the Office of Inter-American Affairs - US government agency created to strengthen inter-American cooperation during the war- as she perpetuated negative stereotypes of Latin America. Accordingly, I maintain that her role was to attract and please the American public. She made use of her ability to be funny and sexy at the same time, which, I contend, derived from her place in the racial hierarchy of the time. My paper is novel as it takes for granted some aspects to which attention has already been drawn, such as Carmen Miranda's costumes and accent, and centers on the narrative of her films, unexplored so far.

\section{Keywords (Source: Unesco Thesaurus)}

Carmen Miranda; representation; Latin American women; good neighbor policy; Hollywood; musical comedy; North American history; history of cinema; cinema; stereotypes. 


\section{Carmen Miranda em Hollywood (1939-1945): no centro da tela, à margen da história}

\section{Resumo}

Neste artigo, faço uma análise da personagem que Carmen Miranda — famosa atriz e cantora ainda hoje lembrada como a bombshell brasileira - interpretou entre 1939 e 1945. Proponho explorar como sua presença na tela grande evidencia os desejos e os medos estadunidenses, associados, em parte, à Segunda Guerra Mundial, mas, principalmente, em diálogo com imaginários sobre raça e gênero. Para isso, analiso as comédias musicais em que a atriz apareceu e concentro-me em seu papel nas narrativas. Evidencio que, embora as personagens representadas por Carmen Miranda sejam centrais nos números musicais, aparecem pouco em cena durante os filmes e não realizam ações que permitam o desenvolvimento das histórias. Além disso, demonstro que a atriz não satisfez os padrões de integração hemisférica propostos pelo Escritório de Assuntos Interamericanos — organismo governamental estadunidense criado para consolidar a cooperação interamericana durante a Guerra -, pois perpetuava estereótipos negativos sobre a América Latina. Com base nisso, defendo que a função da atriz esteve relacionada com atrair e agradar o público estadunidense. Ela fez uso de sua capacidade cômica e sexy que, argumento, era derivada do lugar que ocupava na hierarquia racial da época. Meu trabalho é novo, visto que aborda alguns aspectos sobre os quais se chama a atenção, como o figurino e o sotaque de Carmen Miranda, e concentra-se na narrativa de seus filmes, ponto até agora não explorado.

\section{Palavras-chave (Fonte: tesauro da Unesco)}

Carmen Miranda; representação; mulheres latino-americanas; política de boa vizinhança; Hollywood; comédias musicais; história americana; história do cinema; cinema; estereótipo. 


\section{Introducción}

Carmen Miranda nació en Marco de Canaveses, Portugal, en 1909. Cuando era niña su familia emigró a Brasil en la búsqueda de un futuro mejor. Siendo adolecente empezó a grabar discos y luego a actuar en teatros, casinos y películas. ${ }^{2}$ En 1939, Lee Shubert, empresario de Broadway, llegó al Casino de Urca - prestigioso lugar de encuentro entre las élites brasileñas - en busca de un toque latinoamericano para sus espectáculos. Shubert vio una presentación de Miranda y encontró en ella lo que tenía en mente: tenía el ritmo, el sonido y el color de algo que, siendo exótico, no resultaba amenazador. La invitó a participar en World's Fair, espectáculo de Broadway en el que tuvo gran éxito cantando South American Way (Woll, 1983). Luego de eso Miranda se quedó en los Estados Unidos, continuó participando en comedias musicales en vivo y además comenzó a actuar en las películas del ciclo suramericano de la 20th Century Fox.

Si bien este artículo gira en torno a la figura de Carmen Miranda, está lejos de ser una biografía. Me propongo explorar la manera en la que la presencia de Miranda da cuenta de los deseos y miedos estadounidenses, asociados, en parte a la Segunda Guerra Mundial, pero también en diálogo con discursos sobre las diferencias raciales y de género. Mi análisis se concentra en el periodo de 1939 a 1945. Estas fechas marcan a nivel internacional el comienzo y el fin de Segunda Guerra Mundial, y a nivel hemisférico la vigencia - aunque esta hubiera empezado antes ${ }^{3}$ - de la política de la buena vecindad. Este periodo histórico ha despertado el interés de diferentes investigadores interesados en la historia cultural y de los medios de comunicación, particularmente luego de la década de 1980. Se ha identificado que durante estos años la dimensión cultural del acercamiento hemisférico entró a hacer parte importante de las políticas de Estado estadounidenses, mediante la creación de la Oficina de Asuntos Interamericanos (Office of Inter-American Affairs [OIAA]) (Cramer \& Prutsch, 2012).

2 Durante su tiempo en Brasil actuó en las películas Carnaval Cantado (1932), Alô, alô Brasil! (1935), Estudantes (1935), Alô, alô, Carnaval! (1936) y Banana da Terra (1938) (Bailieiro, 2017, p. 273).

3 Los historiadores siguen debatiendo el comienzo de la buena vecindad, algunos han llegado a localizarlo inclusive en la Administración de Calvin Coolidge (1923-1929). Sin embargo, en términos prácticos, sigue siendo más convincente identificar la buena vecindad con la Administración de Franklin D. Roosevelt (1933-1945). 
Específicamente el caso de Carmen Miranda ha sido tratado por varias académicas. Aquellas investigaciones que se concentran en la Segunda Guerra Mundial pueden ser dividas en dos grandes grupos. Por un lado, encontramos académicas como Shari Roberts (1993), Sean Griffin (2002), Lori Hall-Araujo (2013) y, muy recientemente, Kathryn BishopSanchez (2016) y Fernando Figueiredo Bailieiro (2017), quienes hacen énfasis en la extraordinariamente poderosa presencia escénica de Carmen Miranda y su gran talento para el canto y el baile. Construyen a partir de allí una visión optimista, según la cual la actriz logró subvertir (en lugar de perpetuar) los estereotipos — particularmente de género-que se le imponían, mediante el uso de la exageración, la parodia y los guiños al público. La mayoría de estos estudios están en fuerte diálogo con las reapropiaciones que se han hecho de la figura de Carmen Miranda por parte del público, principalmente el queer, a fin de sostener que Miranda abrió, y continúa abriendo, posibilidades para nuevas representaciones del género y la sexualidad.

Por otro lado, tenemos un segundo grupo de académicas, entre ellas, Ana Rita Mendonça (1999), Tania García (2002), Mara Rúbia Sant’Anna, Káritha Bernardo Macedo (2013), Sol Glik (2010) y Mónica González García (2017), que hace énfasis en el etnocentrismo estadounidense que atraviesa la construcción del personaje de Carmen Miranda. Estos estudios se anclan más fuertemente en el contexto en el que Miranda logró su fama en los Estados Unidos y resaltan los intereses políticos y económicos del Gobierno estadounidense y de los productores de Hollywood. Se hace énfasis en que el ideario panamericanista divulgado por Hollywood pretendía la subordinación de América Latina a los Estados Unidos. Señalan, por ejemplo, la propagación de estereotipos de los latinoamericanos, quienes son caricaturizados como primitivos, infantiles e impulsivos. Específicamente para Carmen Miranda, hacen hincapié en la erotización del personaje, que la torna en objeto de deseo y consumo del espectador.

Podríamos señalar, entonces, que estas dos líneas historiográficas construyen narrativas opuestas sobre Carmen Miranda: en la primera, la actriz es símbolo de subversión y en la segunda de opresión. Este traba- 
jo se inscribe en la narrativa correspondiente al segundo grupo. Esta línea argumentativa es compartida por otros autores como Burton (1992), Purcell (2010) y Pardo (2012), quienes han estudiado las películas de Disney Saludos Amigos (Jackson, Kinney, Luske \& Roberts, 1942) y The Three Caballeros (Ferguson, 1944), caso contemporáneo y comparable al de Miranda. En la literatura mencionada, mi trabajo es novedoso en la medida en que doy por sentado algunos aspectos sobre los que se ha llamado la atención, tales como el vestuario y acento de Carmen Miranda, y me concentro en la narrativa de sus películas, punto hasta ahora inexplorado. Dentro de la vasta producción académica sobre Carmen Miranda, es probable que este silencio esté relacionado con que las cuestiones de raza y género, aspectos que más han llamado la atención de las investigadoras, pueden ser ampliamente analizados desde las presentaciones musicales de la artista. Estas son ricas en información, pues en ellas es posible analizar los trajes, el baile, las expresiones faciales, las letras de las canciones, etc. Además, es justamente en las presentaciones musicales donde Carmen Miranda fue protagonista, razón por la cual resultan más llamativas a la hora de pensar sobre la artista.

Debe recordarse que de las doce películas en las que Carmen Miranda apareció entre 1939 y 1945, nueve de ellas corresponden a comedias musicales producidas por la 20th Century Fox. ${ }^{4}$ Las comedias musicales de la 20th Century Fox se caracterizaron durante este periodo por no incorporar números musicales en los diálogos — integrated structure - como sí lo hicieron otros estudios. Por el contrario, la 20th Century Fox mantuvo la fórmula de presentar historias estandarizadas, divididas por presentaciones de varios artistas, que tenían a menudo poca o ninguna importancia en la narrativa (Griffin, 2002, p. 29). Esto hizo posible que Carmen Miranda fuese el centro de atención en los números musicales, sin necesidad de que tuviera relevancia en las historias. Ahora bien, quiero concentrarme justamente en la manera en que Carmen Miranda se integra, y sobre todo no se

4 Las tres películas restantes son el documental It's All True (Welles, 1993), nunca terminado, y los documentales cortos Meet the Stars: Hollywood Meets the Navy (1941) y The All-Star Bond Rally (1945), ambos estrechamente relacionados con el esfuerzo de guerra en el frente nacional. 
integra, en la narrativa de sus películas. Me intereso por los momentos en que ella está al borde de la historia.

\section{La amenaza nazi y la encrucijada económica de Hollywood}

Durante la presidencia de Franklin D. Roosevelt (1933-1945), los Estados Unidos pasaron en su relación con América Latina de la política del gran garrote a la del buen vecino. Esta nueva postura se tradujo en una serie de estrategias que apuntaban a fortalecer las relaciones económicas, diplomáticas y culturales a lo largo del continente. El cambio puede ser explicado, en parte, por la compleja situación que vivían los Estados Unidos y el mundo en la década de 1930 y durante la Segunda Guerra Mundial. Por un lado, con la llegada de la guerra, se habían cerrado importantes mercados europeos y ante esta situación las emergentes clases medias latinoamericanas prometían convertirse en los nuevos grandes consumidores de los productos estadounidenses. Asimismo, el acercamiento con América Latina resultaba importante para los Estados Unidos a nivel político, pues en 1939 no había ninguna certeza respecto de qué tan lejos podía llegar la avanzada nazi. Se temía que las fuerzas fascistas alcanzaran América Latina y desde allí emprendiera su ataque hacia los Estados Unidos (Goda, 1998). Así, en el imaginario estadounidense, era una cuestión de interés y seguridad nacional mantener al hemisferio fuerte y unido en la defensa contra la amenaza que crecía al otro lado del Atlántico (Cramer \& Prutsch, 2012).

Para ello, la estrategia estuvo enfocada, en parte, en cambiar las representaciones que tanto latinoamericanos como estadounidenses recibían del otro. Con esto se quería lograr un mayor grado de entendimiento y respeto entre todos los americanos. En primer lugar, se buscó romper con los estereotipos negativos que existían a lo largo del hemisferio. Los sondeos estadounidenses señalaron que muchos norteamericanos veían a los latinos como personas sucias, perezosas y carentes de inteligencia. En una encuesta realizada en 1940, que buscaba indagar la opinión pública de los estadounidenses, se les dio a los encuestados una lista de adjetivos y se les solicitó que escogieran todos los que les parecieran adecuados para describir a las personas de Centroamérica y Suramérica. Menos del $15 \%$ de los encuesta- 
dos escogieron los adjetivos "inteligente", "generoso" $\mathrm{y}$ "honesto", mientras "de piel oscura", "perezoso" e "ignorante" fueron escogidos por el 80, el 41 y el $35 \%$, respectivamente (Cantril \& Strung, 1951, p. 502).

En el camino para lograr desbaratar años de estereotipos y representaciones negativas, el cine fue usado como medio propagandístico privilegiado tanto en los Estados Unidos como en el extranjero (Bender, 2012). Se veía en el uso del cine dos grandes ventajas. Por un lado, el cine, más allá que la prensa y la radio, tenía la capacidad de incorporar imagen y sonido, por lo que se le reconocía una fuerza comunicativa mayor. ${ }^{5}$ Por otro, era un producto cultural tradicionalmente entendido como de puro entretenimiento, lo que significaba que las personas lo consumían con los "escudos abajo", no a la espera de ser bombardeadas con mensajes diseñados para influir en su manera de pensar.

Durante la guerra, "gran parte de la industria cinematográfica trató exclusivamente con la Oficina de Información de Guerra (Office of War Information [OWI]), organismo dependiente del Departamento de Estado, que se encargaba, entre otras, de supervisar la producción y la distribución de productos cinematográficos en todo el mundo" (Pardo, 2012, p. 92). Sin embargo, lo relacionado con América Latina quedó bajo responsabilidad de la OIAA. La OIAA fue creada por orden del Consejo de Defensa Nacional el 16 de agosto de 1940. Liderada por el joven multimillonario Nelson A. Rockefeller, su objetivo principal fue persuadir a gobiernos e individuos en toda América Latina, así como al público en el frente doméstico, sobre la vital importancia de la solidaridad y defensa hemisféricas en la lucha contra la infiltración y dominación del Eje (Sadlier, 2012, p. 2).

A su vez, la coyuntura de la guerra también generó una respuesta en los estudios de Hollywood. Hasta finales de la década de 1930, el éxito económico de la industria fílmica estadounidense dependía en gran parte del

5 En una comunicación entre John Hay Whitney, director de la Motion Picture Division, y Nelson A. Rockefeller, director de la OIAA, fechada el 1 de mayo de 1942, se puede leer: de los tres brazos de la guerra psicológica —radio, noticias y películas - este último tiene, por mucho, las mayores potencialidades, gracias a que combina el impacto de lo visual y lo auditivo (citado por Sadlier, 2012, p. 37). 
mercado mundial. Como señalan Koppes \& Black (1990), el $40 \%$ de los ingresos de la industria se generaron en el extranjero, lo que representaba para muchas películas el margen de beneficio. Para algunas compañías, lo recogido fuera de los Estados Unidos representó un porcentaje aún mayor, que llegó inclusive al 50 \% (p. 21). Entre el mercado mundial, el europeo era el más importante. Mientras en América Latina y Asia unos 5000 y 6000 cines, respectivamente, exhibían películas estadounidenses, en Europa existían más de 35 000, donde la producción estadounidense estaba presente regularmente. Sin embargo, a la vez que la influencia del nazismo se expandía por Europa, los mercados para Hollywood fueron disminuyendo, y para 1940 ya eran casi inexistentes. Bajo este panorama fue necesario buscar nuevos consumidores y la creciente clase media latinoamericana se vio como una posible salida al problema.

Dado el interés en vender en América Latina, Hollywood deseaba evitar cualquier contenido que pudiera ser censurado por los gobiernos latinoamericanos o que incomodara o hiriera las sensibilidades de las audiencias de estos países. De ahí que les fuese útil el consejo —o más bien censura suave - que la OIAA hacía sobre sus películas. Al mismo tiempo, a los estudios de Hollywood les convenía usar temas y actores latinoamericanos para agregarle un toque de exotismo a sus películas, ahora que París, Roma y demás ciudades europeas no eran escenarios posibles para sus historias. Lo prolífico de la relación entre el Gobierno y la industria de Hollywood se ve en las cifras. Según información recopilada por De Usabel (1982, p. 162), el total de las 84 películas con temas latinoamericanos producidas en Hollywood durante la Segunda Guerra Mundial fueron elaboradas en cooperación con la OIAA. Sin embargo, lo anterior no significa que el Gobierno estadounidense tuviera pleno control sobre lo que se producía en Hollywood. Entre muchos otros, el caso de Carmen Miranda es ejemplo de cómo el discurso del panamericanismo manejado por Hollywood no coincidió siempre con los lineamientos de la OIAA. A continuación, explicaré algunos aspectos en los que el ciclo de películas con temas suramericanos de la 20th Century Fox respondió a las ideas propuestas por la OIAA. Luego, pasaré a abordar cómo la narrativa presente en estas películas no obedeció a los lineamientos de la oficina de Nelson A. Rockefeller. 


\section{Las comedias musicales en el esfuerzo de guerra}

A finales de la década de 1930, las comedias musicales habían prácticamente desaparecido de la pantalla grande estadounidense. La Segunda Guerra Mundial le dio una nueva vida a este género cinematográfico, que emergió de entre las cenizas para convertirse en uno de los géneros más apreciados del periodo de guerra. Se ha dicho que el éxito de las comedias musicales consistió en su capacidad de alejar a los espectadores de la realidad; de darles, al menos durante un par de horas, un respiro de sus problemas y regalarles la distracción de una trama ligera y divertida. Esta percepción del musical como un género "escapista" corresponde con la realidad de lo ocurrido algunos años atrás. Así fue durante la Gran Depresión, momento en el que las películas musicales permanecieron curiosamente divorciadas de las tensiones que afectaron a la sociedad estadounidense (Woll, 1983, p. 30). Sin embargo, encuentro que los musicales de la Segunda Guerra Mundial son prueba de que la desarticulación con la realidad no es transversal a toda la historia de los musicales. En la primera mitad de la década de 1940, vemos en pantalla mujeres y hombres que hacen su aporte al esfuerzo de guerra. Es el caso de las producciones Yankee Doodle Dandy (Curtiz, 1942), This is the Army (Curtiz, 1942), Broadway Rhythm (Ruth, 1944) y Rosie the Riveter (Santley, 1944), entre muchas otras.

Más específicamente, los musicales resultaron ser uno de los géneros más importantes en el esfuerzo por consolidar un frente hemisférico. 20th Century Fox fue el estudio más activo, al producir entre 1939 y 1945 un promedio de dos musicales con temas latinoamericanos por año. Los musicales de la 20th Century Fox, incluso aquellos que no trataban directamente con temas de guerra, obedecieron a las lógicas de la guerra e intentaron promover el panamericanismo. No se intentó ocultar el mensaje de acercamiento hemisférico. En los exploitation books ${ }^{6}$ consultados en la New York Public Library for the Performing Arts, se encuentra que incluso se intentó usar el acercamiento panamericano como estrategia publicitaria. Por ejemplo, en el lanzamiento de la película Springtime in the Rockies (Cummings, 1942), se les propuso a las diferentes salas de cine hacer una

6 En estos libros, se reunían las estrategias publicitarias propuestas por los estudios para que periódicos y salas de cine en diferentes ciudades promovieran sus películas. 
gala a la que se invitaran "nativos de los distintos países latinoamericanos", en alusión al número musical Panamericana Jubilee. Se propuso, además, decorar las fachadas y los vestíbulos de los cines con banderas latinoamericanas y pancartas coloridas, y entregar premios a los más talentosos cantantes y bailarines, así como a la mujer que mejor imitara a Carmen Miranda (“Cinema Press Books", 1942).

Ahora bien, aunque la 20th Century Fox fue receptiva a la solicitud de la OIAA de promover un llamado al panamericanismo e incluyó actores y actrices latinoamericanos en el reparto de sus películas, no fue completamente fiel a los lineamientos propuestos por la oficina de Rockefeller. Puntualmente, la representación que Carmen Miranda hizo de las mujeres latinoamericanas no obedeció a directrices de la OIAA, que explícitamente había pedido no adjudicarles a los latinoamericanos un exagerado broken English o asumir que todas las personas usaban trajes folclóricos en la vida cotidiana (Memorandum de la Motion Picture Society for the Americas dirigido al Foreign Committee, 19 de agosto de 1941, citado por Orozco, 2016, p. 38). A continuación, presento una reflexión en torno a la narrativa de las películas en las que apareció Carmen Miranda, para señalar aspectos que, si bien no estuvieron directamente en contra de las indicaciones de la OIAA, sí nos permiten darle fuerza a la idea de que Carmen Miranda fue un personaje construido desde el etnocentrismo estadounidense, que perpetuó ideas estereotipadas de las mujeres latinoamericanas.

\section{Carmen Miranda: la inmutabilidad del personaje}

Carmen Miranda tuvo durante los años de la guerra un contrato de exclusividad con la 20th Century Fox. Betty Grable —otra gran estrella de los musicales de guerra - se comprometió en 1940 por diez años con ese mismo estudio. Aunque los contratos de Grable y Miranda tienen en común una cláusula de exclusividad a largo plazo, no significa que las dos actrices estuvieron en igualdad de condiciones para negociar sus películas y papeles. Mientras Miranda quedó atrapada en el mismo tipo de roles, ya en 1941 se ampliaron las posibilidades de actuaciones de Grable al incluirla en el re- 
parto de dos películas con tono más serio de las que ella había hecho hasta entonces. En la primera, A Yank in the R.A.F (King, 1941), Grable hace el papel de Carol Brown, trabajadora de la Fuerza Aérea Auxiliar Femenina durante el día y cantante de un club nocturno durante la noche. En la segunda, un film noir titulado I Wake Up Screaming (Humberstone, 1941), Grable hace el papel de Jill Lynn, la hermana de un joven modelo asesinado. Luego de estas primeras exploraciones, vinieron para Grable los éxitos Song of the Islands (Lang, 1942) y Footlight Serenade (Ratoff, 1942). En 1942, la 20th Century Fox comenzó a trabajar en convertir la historia corta "Second Honeymoon", de Philip Wylie's, en un guion adecuado para explotar los talentos de Grable. El resultado fue Springtime in the Rockies. El gran éxito de la película llevó a la 20th Century Fox a aumentarle su salario y le dio a la actriz mayor poder de decisión sobre las películas que haría de ahí en adelante.

Puede que el caso de Grable haya sido excepcional, dado el increíble éxito de la actriz, quien logró un récord al aparecer doce años consecutivos en el top ten de box office stars. Sabemos que, en general, en la era de los estudios de Hollywood, los actores fueron contratados y asignados para representar los roles que los ejecutivos consideraban apropiados (RamírezBerg, 2008, p. 87). Sin embargo, el extremo al que llega el caso de Carmen Miranda no deja de ser extravagante. Ella mantuvo su traje compuesto por turbante, camisa corta y falda larga, sandalias de plataforma, aretes y brazaletes (una versión blanqueada y erotizada de los trajes tradicionales de las mujeres de Bahía), durante toda su carrera artística. Más allá de la ropa, lo impresionante en el caso de Miranda es que ella se encontró atrapada en el personaje que iba con el vestuario. Según las convenciones de los musicales producidos por la 20th Century Fox durante esta época, siempre debía haber una razón lógica para que los actores y las actrices bailaran y cantaran, por lo que se incluían presentaciones tipo Broadway en la historia (Griffin, 2002). Sin embargo, en estas películas, Miranda nunca deja de actuar como si estuviera dentro de un espectáculo, sin importar lo que ocurría en la historia. Esto llega a su nivel más ridículo en The Gang's All Here (Berkeley, 1943), cuando vemos que Dorita — personaje representado por Mirandaduerme con un pijama que incluye un turbante con frutas. 
La manera en la que se diluyó la diferencia entre Carmen Miranda la persona y Carmen Miranda el personaje está en perfecta concordancia con el hecho de que, en cuatro de sus doce musicales, ella aparece haciendo el papel de sí misma según la ficha técnica de las películas. En el mismo sentido, en el documental Meet the Stars: Hollywood Meets the Navy (1941), en el que aparecen diferentes actores (entre ellos Linda Darnell y George O’Brien), vemos cómo Miranda es la única quien, en su interacción con los miembros de la Marina de guerra, continúa actuando como si su presencia hiciera parte de un espectáculo. Mientras los demás hablan con los soldados y aprenden a usar algunos de los equipos de combate, ella baila en su traje de "bahiana".

$\mathrm{Al}$ respecto, Roberts (1993) sostiene que, aunque Carmen Miranda ofrece varias imágenes negativas de los latinoamericanos y de las mujeres, su persona también revela estas imágenes como estereotipos, por lo que se permite su negociación. Según explica, la representación auditiva y visual que Miranda hacía de sí misma como out-of control excess fue, de hecho, una demostración de su hypercontrol sobre su propia voz e imagen (p. 18). Apuntando en la misma dirección, Bishop-Sanchez (2016) acuña la idea de guiño performativo, para resaltar el compromiso de Miranda con la construcción de su imagen y negar que fue instrumentalizada por un sistema de representación etnocéntrico. En mi opinión, las posiciones sostenidas por Roberts y Bishop-Sanchez muestran una visión demasiado optimista de la situación. No puede olvidarse que Miranda nunca pudo ponerse diferentes máscaras y jugar de diferentes maneras en distintos momentos. Ella fue, siempre, the lady in the tutti-frutti-hat. No era admisible que su cuerpo, en tanto mujer latinoamericana, representara una "parodia” diferente. Es más, con el fin de la guerra, se acaba la carrera de Miranda. No niego que luego de 1945 su imagen fue reapropiada para usos comerciales, incluso publicidad de artículos como maquillaje (Mendonça \& Shaw, 2017), y también como mecanismo de construcción de identidad de las culturas gay y drag (Bailieiro, 2017; Bishop-Sanchez, 2016). Sin embargo, quiero hacer énfasis en que una vez el Gobierno estadounidense dejó de necesitar acercarse culturalmente a América Latina y la industria fílmica perdió el interés en promover el panamericanismo como estrategia comercial, Miranda como 
actriz perdió inmediatamente su protagonismo en Hollywood. De ahí, no encuentro posible que ella tuviera un hypercontrol de su imagen.

Dentro de su optimismo, Roberts (1993) también resalta la fortaleza y agencia del personaje de Carmen Miranda, en contraposición a los papeles desempeñados por sus contrapartes blancas. El argumento de Roberts resulta plausible si se toman elementos aislados de la actuación de Miranda, tales como su fuerte tono de voz y su increíble presencia escénica. Sin embargo, al menos para el periodo acá estudiado, no me es posible respaldar la postura de Roberts. Un análisis detenido de las narrativas desarrolladas en los musicales con temas latinoamericanos de la Segunda Guerra Mundial, revela que estos están marcados por la capacidad de los personajes femeninos estadounidenses de darle forma a la historia, en contraposición a la función de lo que llamo "florero narrativo", desempeñada por Carmen Miranda.

\section{Carmen Miranda: el florero narrativo}

Un aspecto clave en la narrativa de prácticamente todas las películas de ficción son los "puntos del argumento", es decir, los momentos en los que ocurre algo que desencadena un giro determinante para la historia. Estos puntos pueden estar determinados por cualquier evento, desde la muerte $o$ desaparición de alguien, hasta la revelación de un secreto o la consecución de un logro (Corrigan, 2012). Lo impactante de los personajes de Carmen Miranda es que, en contraposición a la importancia que se les daba en la publicidad y lo centrales que eran en los números musicales, estos aparecen poco en escena durante el resto de las películas y no llevan a cabo acciones que permitan el desarrollo de la historia.

Lo anterior tiene una influencia en cómo los espectadores se relacionan con Miranda, pues, por regla general, al ver una película el público suele identificarse con el personaje que muestra inteligencia, racionalidad e ingenio en sus diálogos y acciones (Corrigan, 2012). Así, el hecho de que Miranda no tenga importancia narrativa, su actitud suela ser torpe y sus diálogos muestran típicamente procesos de pensamiento lentos, poco imaginativos y de corta visión, hace que para nosotros como espectadores nos sea muy 
difícil identificarnos con ella. Esta situación se vuelve más marcada, dado que a los personajes representados por Miranda no se les suele dar ningún tipo de trasfondo. No se dice nada de ellos que le dé al espectador información sobre su pasado, forma de ver el mundo o estado emocional, más allá de la ira producto de los celos, que es caricaturizada.

La función de florero narrativo de Miranda contrasta con el papel desempeñado por las actrices estadounidenses, quienes generalmente tenían un rol más importante en las historias, algunas veces llegando inclusive a ser el personaje suspicaz que controlaba la situación, mientras el público disfrutaba de la confusión y torpeza de los demás personajes. Es el caso de Alice Faye cuando hace el papel de la baronesa Cecilia Duarte en That Night in Rio (Cummings, 1941). En esta película, el barón Manuel Duarte (Don Ameche), esposo de la baronesa, viaja a Buenos Aires debido a cuestiones de negocios y es reemplazado en una fiesta por su recién descubierto doble, el artista Larry Matin (también interpretado por Ameche). Ni el barón ni Larry saben que la baronesa está al tanto del cambio. Cuando el verdadero barón regresa a casa, intenta jugarle una broma a Cecilia para hacerla creer que se ha acostado con Larry en lugar de con él. Ella, al tanto de todo, le devuelve el engaño pretendiendo tener, en efecto, relaciones con el artista. Así termina la película, de modo que es ella el personaje que ríe de último.

La incapacidad de los espectadores para identificarse con Carmen Miranda no se da solo a nivel narrativo sino también estético. Ejemplo de ello son los encuadres hechos a Carmen Miranda. Dadas las reglas de edición de Hollywood y específicamente de los musicales de la Segunda Guerra Mundial, la duración y el grado de los close-ups son signos de la importancia de los personajes (Corrigan, 2012; Griffin, 2002). Sin embargo, aunque existen imágenes de Carmen Miranda en primer plano cerrado, estas tomas tienen una función distinta de la tradicional. Siguiendo los planteamientos de Mulvey (1999), sugiero que tales tomas no le permiten a ella mostrarse, sino que le permiten al espectador consumir su imagen. De hecho, en ninguna de sus películas se usa un primer plano con el ánimo de acercarse a la profundidad de sus emociones, como sí se hace con otros personajes. Por ejemplo, en la película The Gang's All Here (Berkeley, 1943), la actriz esta- 
dounidense Betty Grable canta muy triste cuando se entera de que su enamorado volverá a la guerra. Para mostrar su sentimiento en pantalla, se le hace una toma larga a su cara, que muestra sus ojos vidriosos llenos de sentimiento. Al contrario, los close-ups a Miranda funcionan simplemente para que sus gestos, trajes y movimientos sean vistos por el público con mayor detalle (Sant'Anna \& Macedo, 2013). Esto está a su vez relacionado con las convenciones de actuación de la época. Mientras a las actrices blancas se les adjudican valores positivos dada la sutileza de sus gestos, la exagerada gesticulación de Miranda tiene una connotación negativa.

La incapacidad de Carmen Miranda para tener presencia narrativa se ve exacerbada por su incapacidad para comunicarse verbalmente. En sus películas y actuaciones, ella no solo no habla bien inglés, sino que tampoco la vemos ser fluida en portugués ni español. Sus canciones son a menudo juegos de sonidos que no significan nada en ningún idioma. Por ejemplo, en la canción Chica Chica Boom Chic, compuesta por Harry Warren y Mark Gordon, Miranda textualmente dice "boom chi-boom chi-boom, boom chiboom chi-boom. It don't make sense. The chica chica boom chic". Al mismo tiempo, en sus películas no habla portugués con nadie, ni siquiera con los otros personajes con quienes por lógica debería hacerlo. Es un claro ejemplo de esto la forma en la que se comunica el personaje de Rosita Murphy, la "secretaria brasileña", interpretada por Carmen Miranda en Springtime in the Rockies (Cummings, 1942), con quienes son sus hermanos en la película. Entre ellos no hablan ni portugués ni inglés, solo un torpe broken English.

Es importante resaltar que su incapacidad para comunicarse adecuadamente mostraba a Miranda como un ser humano corto en capacidades emocionales y sociales. En la película That Night in Rio (Cummings, 1941), cuando Miranda descubre que su enamorado Larry Martin se siente atraído por otra mujer, ella pierde el control de sí misma y le reclama en medio de gritos que confunden el portugués y el inglés. Ante esta situación, su pareja invalida completamente los sentimientos de Miranda y la calla con la diciente expresión: "baja la voz, el inglés no es ese tipo de idioma”. En contraposición, cuando en The Gang's All Here (Cummings, 1943) la corista Edie Allen (Alice Faye) descubre que su enamorado, el 
soldado Andy Mason Jr. (James Ellison), está en realidad comprometido con Vivian (Sheila Ryan), ella, absolutamente deshecha, es capaz de expresar sus sentimientos en palabras y tener una conversación con Andy, en la que, dicho sea de paso, se aclara todo el malentendido.

\section{Carmen Miranda: la sexualización del equilibrio racial}

Hasta ahora he sostenido dos puntos. En primer lugar, argumenté que el caso de Miranda es un ejemplo de cómo a la OIAA no le fue posible revertir por completo la tendencia de los estudios de Hollywood de crear y circular representaciones estereotipadas de las latinoamericanas. En segundo lugar, propuse que Carmen Miranda tampoco contribuyó en términos narrativos para el desarrollo de sus películas, pues ella está ausente en la construcción de las historias. Dada esta situación, cabe preguntarse cuál sí fue la función de Miranda en las películas del ciclo suramericano de la 20th Century Fox. Varias autoras han señalado que ella fue muy atractiva para el público nacional en los Estados Unidos. De ahí es posible presumir que su función tuvo que ver con una estrategia comercial. Ahora, la pregunta central devine entonces ¿por qué Carmen Miranda fue atractiva para el público estadounidense?

Un punto señalado por la historiografía es que su presencia en escena resultaba cómica. Según Bailieiro (2017), por ejemplo, se tomó ventaja de la - supuesta o real — inhabilidad de Miranda para hablar inglés, con el ánimo de provocar risas. Incluso cuando ella ya hablaba inglés bastante bien, mantuvo en público un marcado acento y errores de pronunciación. Por otro lado, en el contexto de cómo estaban estructurados los musicales de la 20th Century Fox, no puede despreciarse lo atractiva que ella era como bailarina y cantante, ya desde su paso por Broadway (Griffin, 2002; Mendonça \& Shaw, 2017). La manera en la que estos elementos cobraron protagonismo debe ser entendida en el contexto de la austeridad producto de la guerra. Tanto lo divertida que resultaba como sus habilidades para cantar y bailar, se veían como resultado natural de su procedencia geográfica. Por tanto, no debían ser explicados en el guion. En otras palabas, recu- 
rrir a estereotipos permitía acelerar la narración y lograr con ello musicales que iban "directo al grano". Tal como lo explica Ramírez-Berg (2008), como práctica puramente industrial, los estereotipos se mantienen debido a su valorada economía narrativa, que también está relacionada con la economía financiera. Debido a que requieren poca o ninguna introducción y explicación, y se comprenden de forma rápida y completa como signos, los estereotipos son un medio extremadamente económico y eficiente de contar una historia en una película (p. 42).

Asimismo, en la construcción del guion tampoco se debía explicar por qué la figura de Miranda resultaba sexualmente sugestiva al bailar, pues también se veía como resultado natural de la procedencia geográfica de la actriz. Autoras como Myra Medible (2007), Karen S. Goldman (2013) y Peña Ovalle (2016) han señalado que el baile latinoamericano ha sido repetidamente relacionado con disponibilidad sexual. De hecho, la relación entre procedencia geográfica y erotismo no funcionaba únicamente en la historia que el espectador consumía, sino que llegó a utilizarse inclusive como argumento para contestar a los intentos de censura. Refiriéndose al traje de "bahiana" diseñado por Gwen Wakeling para que Carmen Miranda utilizara en la película Week-end in Havana (Lang, 1941), Gil-Montero (1989) comenta que la falda causó problemas con la censura debido a las caderas expuestas. En un memo interno del estudio, se explicó que el equipo de vestuario había encontrado fotos del traje original que eran aún más audaces; ya que era importante estar lo más cerca posible al original, la falda fue autorizada (citado por Sant'Anna \& Macedo, 2013, p. 191). Esta jugada retórica resulta particularmente divertida si se recuerda que la fidelidad de los trajes de Miranda al vestuario original de las bahinas nunca fue una preocupación de Hollywood. Piénsese, por ejemplo, que otro traje utilizado por Miranda en Week-End in Havana (Lang, 1941) estaba compuesto por una blusa recargada con esferas plateadas y un turbante con visos relucientes que recorrían largas hojas de plátano, lo que hacía que el conjunto se asemejara más a un árbol de Navidad que a un vestido. Asimismo, algunos años más tarde en Greenwich Village (Lang, 1944), el turbante de Miranda contenía palos de dulce en lugar de frutas. 
No puede perderse de vista que el intento de censura mencionado arriba no fue un caso aislado en la época. Preocupados por los "valores morales" que las películas podían poner en riesgo, y la aparente gran influencia que estas tenían sobre la manera como las personas concebían el mundo, Hollywood creó juntas de censura desde muy temprano en el siglo XX. En 1934, los ejecutivos de la industria fueron un paso más allá y comenzaron a seguir el conservador código escrito por Daniel Lord, S. J., en 1930. Según lo explican Koppes \& Black (1990), el código, una mezcla de la moral conservadora católico-romana y los principios de la decencia burguesa, impuso fuertes restricciones al tratamiento que las películas hacían de una amplia gama de temas (p. 15). Entre otras, tal y como se vio arriba, se limitaba la piel que se mostraba. Podría pensarse, entonces, que luego de 1934 el cine dejó de satisfacer el deseo del público de ver en pantalla imágenes - así fuera mínimamente - eróticas. Carmen Miranda llegó en 1939 a satisfacer ese "nicho vacío", dado que para ella —en contraposición a lo ocurrido con las actrices blancas - era posible mostrarse de una manera erotizada. ${ }^{7}$ Su sexualidad estaba controlada por medio del énfasis en la diferencia.

Según Ramírez-Berg (2008), el mecanismo narrativo utilizado por Hollywood para neutralizar la sexualidad de las latinas en escena era mostrarlas, o bien como promiscuas y criminales, como en el caso del estereotipo de prostituta, o bien como tontas y cómicas, como en el caso de Miranda. Al respecto, me gustaría agregar que la sexualidad de Miranda no solo se controlaba mediante las risas, sino que también desde la narrativa de las películas es posible encontrar otro mecanismo. Nótese que, si bien en sus películas Carmen Miranda resulta supremamente atractiva, ella no parece ser merecedora de la "conquista principesca" típica de las tramas de Hollywood. En sus películas, no solo es imposible que establezca una relación romántica con personajes estadounidenses, sino que esta posibilidad se le niega incluso en el interior del núcleo del "grupo racial" extranjero. Aun-

7 Esto no significa que las mujeres estadounidenses no estuvieran fuertemente sexualizadas, cosificadas y fueran consumidas por el público. El ejemplo más claro de ello es la manera en la que se habló en la época de las famosas piernas de Betty Grable, que la 20th Century Fox inclusive llegó a asegurar por un millón de dólares como truco publicitario (Sonneborn, 2002). 
que Miranda sea emparejada románticamente con hombres de su "misma nacionalidad” (argentinos, brasileños o cubanos, según la película), este amor no es suave, racional y "civilizado", como en el caso de los estadounidenses. En realidad, este "romance étnico" funciona como la contraparte cómica del amor serio de la pareja principal (Roberts, 1993).

Al mismo tiempo, no todo en la imagen de Miranda hacía énfasis en la otredad y en la diferencia. Su representación de la mujer bahiana/brasileña/latinoamericana estaba "blanqueada", y así borraba la herencia negra en América Latina, invariablemente vista como negativa (Mendonça, 1999). Por ejemplo, si bien ella siempre utilizó el traje de "bahiana", su apariencia física - pelo liso y piel relativamente clara — la distanció de la gran mayoría de la población de Bahía y de la población afrodescendiente estadounidense. Esto es importante, pues gracias a ello Carmen Miranda no fue vista como tan diferente como para ser completamente marginalizada en las películas y tenía la posibilidad de no aparecer únicamente en los números musicales, sino tener —alguna - interacción con los personajes blancos. En contraposición, debe recordarse que, en varias películas de Hollywood con escenarios estadounidenses, los negros estaban tan fuertemente segregados que se llegó inclusive al nivel en el que sus números habitualmente empezaron y terminaron con una toma de la audiencia aplaudiendo o de una cortina subiendo o bajando (Woll, 1983, p. 122), lo que los mantenía alejados de interactuar con personajes blancos.

Además, el blanqueamiento de América Latina para el consumo de los estadounidenses no se ve solo en la apariencia física de la actriz, sino en su vestuario, que solía ser una versión occidentalizada del original (HallAraujo, 2013). Algunas autoras como Roberts (1993), Mandrell (2001), Bishop-Sanchez (2016) y Bailieiro (2017) han señalado que el traje de bahiana ya había sido apropiado por Miranda cuando ella vivía en Brasil y entienden por ello que este no podía estar atravesado por el etnocentrismo estadounidense. Para ellas se trata, por el contrario, de una encarnación de lo afrobrasileño. Esta argumentación falla por dos razones. En primer lugar, no puede olvidarse que el traje se fue distorsionando cada vez más durante el paso de Miranda por Hollywood. Es decir, no se mantuvo la imagen que 
ella trajo de Brasil. En su primera película, ya no hay cerezas, peras y papayas en su turbante, sino que el énfasis recae exclusivamente sobre los plátanos, fruta que los estadounidenses han relacionado con las banana republics y, por extensión, con toda América Latina. Luego, película tras película, el traje de Miranda se fue degenerando y llegó en ocasiones incluso a extremos ridículos como el mencionado arriba, cuando hubo palos de dulce en lugar de fruta sobre su cabeza. En segundo lugar, pero más importante, no podemos pensar a Brasil como un paraíso tropical alejado del discurso modernizador global. Incluso antes de que el traje llegara a los Estados Unidos, ya en Brasil el vestuario característico de Carmen Miranda había atravesado un proceso de blanqueamiento, asociado en parte a la política nacionalista de Getulio Vargas. ${ }^{8}$ Es decir, no porque Miranda tuviera el traje de "bahiana" desde Brasil, significa que este deba ser entendido como "puro".

Sostengo, entonces, que la principal función de Carmen Miranda, no siendo narrativa ni de auténtico acercamiento interamericano, fue la de atraer al público estadounidense mediante la liberación de tensiones acumuladas. Ella pudo hacer esto dado que las audiencias la percibían como cómica y sexualmente atractiva, dentro de una lectura etnocéntrica que la posicionaba a ella como una otra moderadamente asimilable. Ella no era negra, por lo que su imagen no era vista como amenazante y sobre ella no recaín los códigos segregacionistas de Hollywood. Al mismo tiempo, era la única actriz famosa en los musicales de guerra que no era rubia. Entonces, mientras las otras grandes artistas - Betty Grable, Alice Faye y Vivian Blaine- no podían violar las convenciones morales del código de censura, Miranda sí, pues su sexualidad podía ser justificada y controlada mediante otros mecanismos, entre ellos, el "humor" racista. Eso la convertía en la única artista a través de la que las audiencias estadounidenses podían vivir hasta cierto punto una sexualidad que había sido reprimida en pantalla luego de 1934. El hecho de que a través de la risa y el desfogue sexual Miranda se convirtiera en la encarnación de lo que el público estadunidense deseaba-rechazaba comprueba, nuevamente, que los estereotipos no revelan nada sobre el objeto estereotipado, sino que nos dan información sobre quién estereotipa.

8 Para información sobre el proceso de blanqueamiento de la cultura negra en Brasil, véase Andrews (2007). 


\section{Conclusiones}

Hollywood cooperó hasta cierto punto con los lineamientos sugeridos por la OIAA en pro de un acercamiento cultural interamericano, que incluyó en sus películas, por ejemplo, temas y actores latinoamericanos. Sin embargo, durante los años de la Segunda Guerra Mundial la industria continuó utilizando representaciones que, aunque potencialmente ofensivas para las audiencias en América Latina, resultaron muy llamativas para el mercado nacional. En este marco se inscribió el personaje de Carmen Miranda. La exotización y erotización que se hizo de la actriz nos muestra cómo la construcción de las imágenes está atravesada por relaciones de poder que permiten asignarles unos atributos a unos grupos y no a otros. Específicamente, entre 1939 y 1945, se configuró el atractivo personaje de Miranda a partir de la explotación y perpetuación de ideas racistas y sexistas que la ponían a ella entre lo espectacular, lo cómico y lo erótico.

Carmen Miranda no trascendió la imagen estereotípica de las mujeres latinoamericanas, como han sostenido algunos estudios sobre ella. Al contrario, perpetuó estereotipos de raza y género que cargamos en nuestros cuerpos todas las mujeres latinoamericanas — una estrategia profesional que se asemeja a algunas de las patriarcal bargaining estudiadas por Kandiyoti (1988). Es más, Carmen Miranda perpetuó estereotipos que la afectaron inclusive a ella misma, pues nunca pudo salir de su rol de torpe/ cómica, sexi/exótica, latina que baila. Una mirada a la narrativa de las comedias musicales en las que apareció Carmen Miranda nos mostró que incluso dentro de las mismas películas, si bien en ocasiones ella logró estar en el centro, por ejemplo, en los números musicales, siempre estuvo al margen de la historia.

En atención a lo anterior, nombré su presencia en escena como "florero narrativo". Un recipiente vacío que se llena con aquellas cosas exteriores con las que de manera controlada se quiere decorar el interior. El florero funciona como un descanso visual: en la casa al llegar del trabajo en los Estados Unidos en un contexto de guerra y en la pantalla entre los conflictos del guion. En su posición de florero narrativo a Carmen Miranda le fue posible embellecer las películas. No tuvo un rol en la narrativa y su imagen 
tampoco contribuyó a un verdadero acercamiento interamericano, pero funcionó bien para liberar las tensiones del público en los Estados Unidos. Ella pudo estar presente en las películas, dentro de una lectura etnocéntrica que diseñaba, recortaba y demilitaba su exoticidad, tal como las flores del jardín con licencia temporal para habitar nuestra sala.

Ahora bien, lo anterior no significa que Carmen Miranda haya sido simple y únicamente una víctima. Gracias a características individuales, tales como su increíble talento escénico y su gran belleza, Miranda logró obtener grandes beneficios aun en las jerarquías de raza y género. Esto hace que no podamos pensarla únicamente desde el punto de vista de la opresión, pues el personaje representado por ella resultó ventajoso para la actriz como individuo. Sépase que ella fue la artista mejor pagada en los Estados Unidos durante la guerra, y en 1945 se convirtió en la mujer mejor pagada en los Estados Unidos al recibir USD 200000 (Glik, 2012). Ese año su lugar en la lista de ingresos estuvo inmediatamente después del director de la General Motors (Guerra, 2004).

Quisiera cerrar indicando que, si bien existen abundantes y variados estudios sobre Carmen Miranda, aún queda mucho por hacer. Hace falta información sobre algunas etapas de su carrera artística, sobre todo su paso por la radio y la grabación musical. Además, será igualmente enriquecedor que investigaciones futuras aborden a partir de este y otros casos aspectos de la industria como el star system de Holllywood y aspectos culturales como los imaginarios sobre lo femenino, la familia, el amor romántico, etc.

\section{Referencias}

Andrews, G. R. (2007). Afro-Latinoamérica 1800-2000. Madrid, España: Iberoamericana.

Balieiro, F. F. (2017). Consuming Carmen Miranda: Dislocations and dissonances in the reception of an icon. Revista Estudos Feministas, 25(1), 269-290. DOI: http://dx.doi.org/10.1590/18069584.2017v25n1p269 
Bender, P. (2012). “There's Only One American Now”: The OIAA Film Program in the United States. En G. Cramer y U. Prutsch (Eds.), ¡Américas Unidas! Nelson A. Rockefeller's Office of Inter-American Affairs (1940-46) (pp.77-105). Madrid, España: Iberoamericana.

Bishop-Sanchez, K. (2016). Creating Carmen Miranda: Race, camp, and transnational stardom. Nashville, EE. UU.: Vanderbilt University Press.

Burton, J. (1992). Don (Juanito) Duck and the imperial-patriarchal unconscious: Disney Studios, the Good Neighbor Policy, and the packaging of Latin America. En A. Parker, M. Russo \& P. Yaeger (Eds.), Nationalisms \& sexualities (pp. 21-41). Nueva York, EE. UU.: Routledge.

Cantril, H. E. \& Strunk, M. E. (Eds.) (1951). Public opinion 1935-1946. Princeton, EE. UU.: Princeton University Press.

Cinema Press Books [Microfilm]. (1942). Nueva York, EE. UU.: New York Public Library for the Performing Arts, Billy Rose Theatre Division.

Corrigan, T. (2012). A short guide to writing about film. Boston, EE. UU.: Pearson.

Cramer, G. \& Prutsch, U. (2012). Nelson A. Rockefeller's Office of InterAmerican Affairs and the quest for pan-American unity: An introductory essay. En G. Cramer \& U. Prutsch (Eds.), ¡Américas Unidas! Nelson A. Rockefeller's Office of Inter-American Affairs (1940-46) (pp. 15-51). Madrid, España: Iberoamericana.

García, T. (2002). Carmen Miranda: Imagem e símbolo da América Latina construído por Hollywood. Ponencia presentada en Idéias, representações e mitos norteamericanos: V Encontro da Associação Nacional de Pesquisadores de História Latino-Americana e Caribenha, Belo Horizonte, Brasil. 
Glik, M. (2010). Yes, tenemos bananas: construcciones de género y raza en los estereotipos plasmados por Hollywood (1930-1955). Ponencia presentada en XIV Encuentro de Latinoamericanistas Españoles: Congreso internacional, Santiago de Compostela, España.

Goda, N. (1998). Tomorrow the World: Hitler, Northwest Africa, and the Path toward America. College Station, EE. UU.: Texas A\&M University Press.

Goldman, K. (2013). Saludos Amigos and The Three Caballeros: The representation of Latin America in Disney's "Good Neighbor" Films. En J. Cheu (Ed.), Diversity in Disney films: Critical Essays on race, ethnicity, gender, sexuality and disability (pp. 23-37). Jefferson, EE. UU.: McFarland \& Company, Inc.

González, M. (2017). Eros imperial: Carmen Miranda y los "cuerpos imaginados” de la buena vecindad. Cine Cubano, 201-202, 60-65. Recuperado de https://www.academia.edu/35459877/Eros imperial_Carmen_Miranda_y_los_cuerpos_imaginados_de_ la_Buena_Vecindad.pdf

Griffin, S. (2002). The gang's all here: Generic versus racial integration in the 1940s musical. Cinema Journal, 42(1), 21-45. Retrieved from https://www.jstor.org/stable/1225541

Guerra, L. (2004). Between history and fiction: The nights of Carmen Miranda. Pacific Coast Philology, 39, 9-16. Retrieved from https:// www.jstor.org/stable/25474150

Hall-Araujo, L. (2013). Carmen Miranda: Ripe for imitation (Tesis de doctorado, Indiana University, Indiana, EE. UU.).

Haraway, D. J. (1995). Conocimientos situados: la cuestión científica en el feminismo y el privilegio de la perspectiva parcial. En Autor, Ciencia, cyborgs y mujeres: la reinvención de la naturaleza (pp.313-346). Madrid, España: Cátedra. 
Kandiyoti, D. (1988). Bargaining with patriarchy. Gender and Society, 2(3), 274-290. DOI: https://doi.org/10.1177/089124388002003004

Koppes, C. R. \& Black, G. D. (1990). Hollywood goes to war: How politics, profits and propaganda shaped World War II movies. Berkeley, EE. UU.: University of California Press.

Mandrell,J. (2001). Carmen Miranda betwixt and between, or, neither here nor there. Latin American Literary Review, 29(57), 26-39. Retrieved from https://www.academia.edu/30547959/_Carmen_Miranda_Betwixt_and_Between_or_Neither_Here_nor_There_

Mendible, M. (Ed.) (2007). From bananas to buttocks: The Latina body in popular film and culture. Austin, EE. UU.: University of Texas Press.

Mendonça, A. (1999). Carmen Miranda foi a Hollywood. Rio de Janeiro, Brasil: Record.

Mendonça, A. \& Shaw L. (2017). Carmen Miranda: From national star to global brand. En T. Bergfelder, L. Shaw \& J. L. Vieira (Eds.), Stars and stardom in brazilian cinema (pp. 73-92). Nueva York, EE. UU.: Berghahn.

Mulvey, L. (1999). Visual pleasure and narrative cinema. En L. Braudy \& M. Cohen (Eds.), Film theory and criticism: Introductory readings (pp. 833-844). Nueva York, EE. UU.: Oxford University Press.

Orozco, M. (2016). Turbantes y bananas: Carmen Miranda y la representación de las mujeres latinoamericanas en las comedias musicales hollywoodienses (1939-1945) (Tesis de grado), Universidad Nacional de Colombia, Bogotá, Colombia.

Pardo, E. (2012). No-retratos de Latinoamérica: Disney y su trabajo para la Oficina de Asuntos Interamericanos (1941-1946). Huellas de Estados Unidos: Estudios y Debates desde América Latina, 2, 91-104. 
Recuperado de http://www.huellasdeeua.com/ediciones/edicion2/articulo\%207.pdf

Peña Ovalle, P. (2016). Dance and the Hollywood Latina: Race, sex, and stardom. New Brunswick, Canadá: Rutgers University Press.

Purcell, F. (2010). Cine, propaganda y el mundo de Disney en Chile durante la Segunda Guerra Mundial. Historia, 43(2), 487-522. Recuperado de https://scielo.conicyt.cl/scielo.php?script=sci_artt ext\&pid=S0717-71942010000200005

Ramírez-Berg, C. (2008). Latino images in film: Stereotypes, subversion, \& resistance. Austin, EE. UU.: University of Texas Press.

Roberts, S. (1993). "The Lady in the Tutti-Frutti Hat": Carmen Miranda, a spectacle of ethnicity. Cinema Journal, 32(3), 3-23. DOI: http:// doi.org/10.2307/1225876

Sadlier, D. J. (2012). Americans all: Good Neighbor Cultural Diplomacy in World War II. Austin, EE. UU.: University of Texas Press.

Sant'Anna, M. R. \& Macedo, K. B. (2013). Images of Latin America in the body and costumes of Carmen Miranda's stylized baiana: Social memory and identity. Comunicação e Sociedade, 24, 186-209. DOI: http://dx.doi.org/10.17231/comsoc.24(2013).1783

Sonneborn, L. (2002). Grable, Betty (Ruth Elizabeth Grable). En A to Z of American Women in the Performing Arts (p. 88). Nueva York, EE. UU.: Facts on File.

Usabel, G. de (1982). The high noon of American films in Latin America. Ann Arbor, EE. UU.: UMI Research Press.

Woll, A. L. (1983). The Hollywood musical goes to war. Chicago, EE. UU.: Nelson-Hall. 


\section{Filmografía}

Audley, M. (Director). (1945). The All-Star Bond Rally [cortometraje]. Estados Unidos: 20th Century Fox Studios.

Berkeley, B. (Director). (1943). The Gang's All Here [película]. Estados Unidos: Twentieth Century-Fox.

Cummings, I. (Director). (1940). Down Argentine Way [película]. Estados Unidos: Twentieth Century Fox Film Corporation.

Cummings, I. (Director). (1941). That Night in Rio [película]. Estados Unidos: Twentieth Century Fox Film Corporation.

Cummings, I. (Director). (1942). Springtime in the Rockies [película]. Estados Unidos: 20th Century Fox.

Curtiz, M. (Director). (1942). Yankee Doodle Dandy [película]. Estados Unidos: Warner Bros.

Curtiz, M. (Director). (1943). This is the Army [película]. Estados Unidos: Warner Bros.

Ferguson, N. (Director). (1994). Los tres caballeros [película]. Estados Unidos: Walt Disney Productions.

Humberstone, H. B. (Director). (1941). I Wake Up Screaming [película]. Estados Unidos: 20th Century-Fox Film Corporation.

Jackson, W., Kinney, J., Luske, H. \& Roberts, B. (1942). Saludos amigos [película]. Estados Unidos: Walt Disney Pictures.

King, H. (Director). (1941). A Yank in the R.A.F. [película]. Estados Unidos: 20th Century-Fox Film. 
Lang, W. (Director). (1941a). Song of the Islands [película]. Estados Unidos: 20th Century Fox.

Lang, W. (Director). (1941b). Week-End in Havana [película]. Estados Unidos: Twentieth Century-Fox Film Corporation.

Lang, W. (Director). (1944). Greenwich Village [película]. Estados Unidos: Twentieth Century Fox Film Corporation.

Meet the Stars: Hollywood Meets the Navy [cortometraje]. (1941). Estados Unidos.

Ratoff, G. (Director). (1942). Footlight Serenade [película]. Estados Unidos: Twentieth Century Fox Film Corporation.

Ruth, R. del (Director). (1944). Broadway Rhythm [película]. Estados Unidos: Metro-Goldwyn-Mayer Studios.

Santley, J. (Director). (1944). Rosie the Riveter [película]. Estados Unidos: Republic Pictures.

Seiler, L. (Director). (1944). Somethingfor the Boys [película]. Estados Unidos: Twentieth Century Fox Film Corporation.

Seiler, L. (Director). (1945). Doll Face [película]. Estados Unidos: 20th Century Fox.

Seiter, W. A. (Director). (1944). Four Jills in a Jeep [película]. Estados Unidos: Twentieth Century Fox Film Corporation.

Welles, O., Krohn, B., Meisel, M., Wilson, R. y Foster, N. (1993). It's All True [documental]. Francia: Coproducción Francia-Estados Unidos. 